\title{
Design of an Air-Sparged Tubular Photocatalytic Reactor for the Degradation of Methylene Blue: Mass-Transfer Limitation Studies
}

\author{
Patrick Ramoso ${ }^{1, a}$ and Maria Lourdes Dalida ${ }^{1}$ \\ ${ }^{1}$ Department of Chemical Engineering, University of the Philippines Diliman, Quezon City, Philippines
}

\begin{abstract}
An alternative process for the removal of organic pollutants in aqueous systems is photocatalysis. The challenges hindering its industrial use are electron-hole recombination and mass-transfer limitations. In order to address these problems, the objective of this study is to introduce air by sparging, and design an air-sparged photocatalytic reactor using titanium dioxide immobilized on borosilicate glass. The performance of the reactor on the removal of the model pollutant, methylene blue (MB), was evaluated and compared against the reactor operated without sparging. The effect of mass-transfer limitations on reactor performance was also investigated by regression using a Langmuir-type model equation. The sparged photocatalytic reactor was able to degrade $57 \% \mathrm{MB}$ in 2 hours, an improvement of $40 \%$ compared to no sparging, and is comparable to similar reactors in literature, but with the advantage of using less expensive materials of construction and simpler immobilization technique. Mass-transfer limitation studies showed a good fitting of the initial reaction rate $r$, with $r=0.1399 Q /(0.6120+Q)$ for the sparged operation, and $Q$ is the volumetric flowrate of water $(\mathrm{L} / \mathrm{min})$. The model also shows that the reactor operates near the reaction-limited regime, and that the extent of mass-transfer limitation effects was reduced by the present reactor.
\end{abstract}

\section{Introduction}

The development of advanced wastewater treatment processes has been well studied over the years in light of the detrimental effects of water pollution, particularly organic compounds coming from industrial effluents. These treatment processes are classified under physical, chemical or biological $[1,2]$. These treatment processes, however, have their own limitations. For example, adsorption processes have a problem with the disposal of spent adsorbent; chemical treatment processes may cause the formation of harmful byproducts; and biological processes are feasible only for contaminants that are not toxic to the microbes present in the system.

An alternative to these processes is photocatalysis, which uses ultraviolet or visible light to initiate the degradation of organic pollutants using a photocatalyst, resulting to complete mineralization [2-5]. Photocatalysis offers an alternative because the degradation of pollutants is complete - there are no unwanted byproducts; there is no transfer of pollutants from one phase to another; and its application is a wide range of pollutants.

Photocatalytic reactors may be classified either as suspended or immobilized systems. Suspended systems, although they have higher activity, have a problem of requiring post-process separation since the photocatalyst is finely dispersed within the water being treated. This lowers the economic viability of these systems [3, 5]. Post-process separation is not required in immobilized systems, as the photocatalyst is anchored on a support.

\footnotetext{
a Corresponding author: pdramoso@up.edu.ph
}

Immobilized systems, however, also have problems of their own, such as mass-transfer limitations and electronhole recombination, with the latter covering both immobilized and suspended systems. High mass transfer resistances result to a reactant concentration gradient between the bulk fluid and photocatalyst surface, resulting to lower rates of reaction [6]. Electron-hole recombination occurs as the excited electron in the conduction band returns and fills up the positive hole in the valence band. The series of reactions ceases, and photocatalytic activity decreases [3].

Mass-transfer limitations are manifested by the dependence of the reaction rate $r$, or the apparent rate constant $k_{\text {app }}$, on the liquid velocity. Various studies have identified the existence of mass-transfer limitations in many immobilized systems, such as tubular reactors [7-8], annular reactors [9-11], rotating disc reactors [9, 12], and packed-bed reactors [7, 13], among others [14]. A commonly used model equation derived from first principles is a Langmuir-type equation based on volumetric flowrate $Q$ [15-16]:

$$
r\left(\text { or } k_{\text {app }}\right)=a b Q /(1+a Q)
$$

These two challenges are to be addressed by introducing air into the system by sparging. Adding air bubbles lessens the effect of mass-transfer limitations by promoting mixing of the liquid phase. Introducing air into the system adds an electron-scavenger into the system, with oxygen accepting excited electrons to form the superoxide ion. This leaves the holes available for 
mineralization to take place. The objective of this study is to design an air-sparged, tubular photocatalytic reactor using $\mathrm{TiO}_{2}$ and study the effect of mass-transfer limitations on its performance.

\section{Materials and Methods}

\subsection{Reactor design}

The reactor consists of five tubes radially arranged with a total reactor volume of $600 \mathrm{~mL}$, and a 10W UVA lamp placed at the center of the reactor, as shown in Figures 12. The tubes are made of borosilicate glass, and are fabricated with internal protrusions to promote turbulence and provide additional surface area for the catalyst [17]. The catalyst, Aeroxide ${ }^{\circledR} \mathrm{P} 25 \mathrm{TiO}_{2}$, was immobilized onto the tubes by spray coating with ethanol as carrier, and the tubes were dried and calcined in a muffle furnace. Air is sparged through nozzles directed at each tube such that the bubbles rise along the tubes as the water descends.

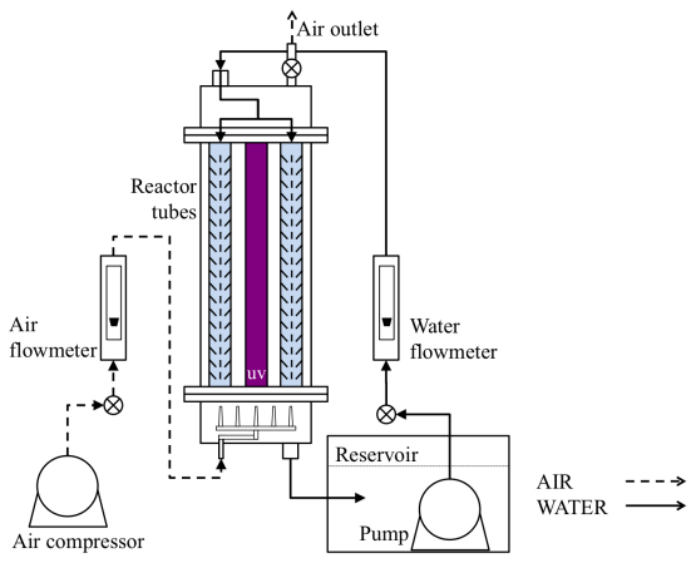

Figure 1. Diagram of Photocatalytic Reactor System

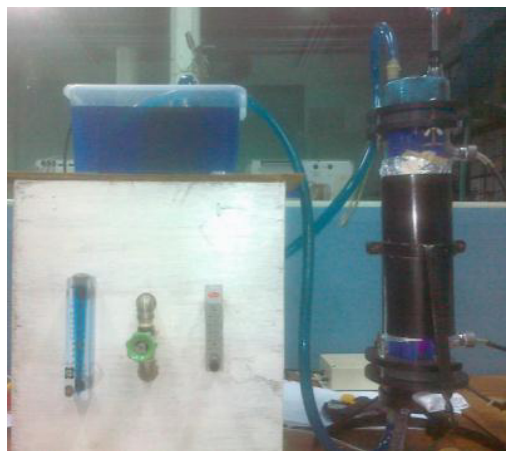

Figure 2. Actual Photocatalytic Reactor Set-up

\subsection{Catalyst characterization}

Samples of the immobilized photocatalyst were obtained by the destruction of one reactor tube after its calcination in order to characterize its surface. This was done by scanning electron microscopy (SEM) using a Hitachi S3400-N Scanning Electron Microscope. Images of surface were obtained at $300 \mathrm{x}$ and $1000 \mathrm{x}$ magnification [18].

\subsection{Reactor performance evaluation}

The performance of the reactor, measured as percent removal of methylene blue (MB), under sparged and nonsparged operation was compared at the following process parameters: $2.69 \mathrm{ppm}$ initial $\mathrm{MB}$ concentration, $\mathrm{pH}$ 7, 2.8 liters per minute $(\mathrm{L} / \mathrm{min})$ water flowrate [17], and 2.0 $\mathrm{L} / \mathrm{min}$ air sparging rate, at 30, 60, 90 and 120 minutes. Adsorption (dark) and blank (no photocatalyst) runs were done as control [18]. Methylene blue concentration was analyzed using a PerkinElmer Lambda 850 UV/VIS Spectrometer at a peak wavelength of $665 \mathrm{~nm}$.

\subsection{Mass-transfer limitation studies}

The effect of mass-transfer limitations on the reaction rate was modeled for the sparged and non-sparged operation of the photocatalytic reactor using $2.69 \mathrm{ppm}$ initial $\mathrm{MB}$ concentration and $\mathrm{pH} 7$, with a sparging rate of 2.0 LPM. To determine the effect of mass-transfer limitations, the water flowrate was varied to $Q=1.2,1.6$, 2.0, 2.4 and 2.8 LPM. The initial rate of reaction, $r$, was determined based on the difference between initial and final MB concentrations for a period of 20 minutes [18]. A Langmuir-type model equation was used, particularly was used to relate the initial reaction rate to the volumetric flowrate. The model constants $a$ and $b$ were determined by regression analysis.

$$
r=a Q /(b+Q)
$$

\section{Results and Discussion}

\subsection{Catalyst characterization}

SEM images of the reactor tube surface are presented in Figures 3-4. It could be seen that the catalyst was immobilized throughout the surface of the glass; however, the coating is not uniform. The presence of wavelike patterns indicates a high surface area provided by the roughness of the immobilized surface; this morphology has been reported to increase photocatalytic activity [19]. In addition, the high magnification image in Figure 4 illustrates the roughness of the surface, which may have resulted from the agglomeration of $\mathrm{P} 25 \mathrm{TiO}_{2}$ particles upon spray coating.

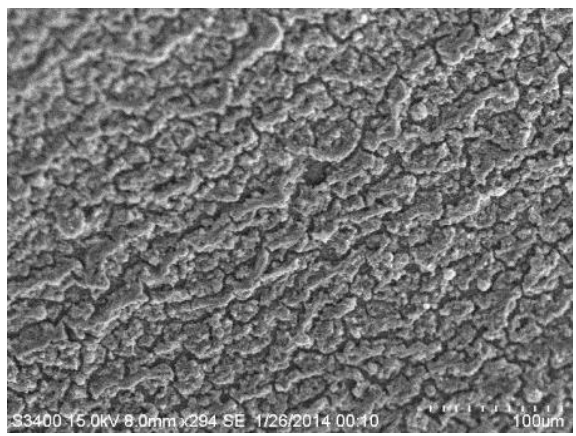

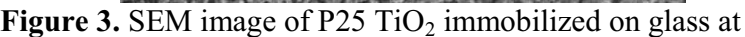
300x magnification 


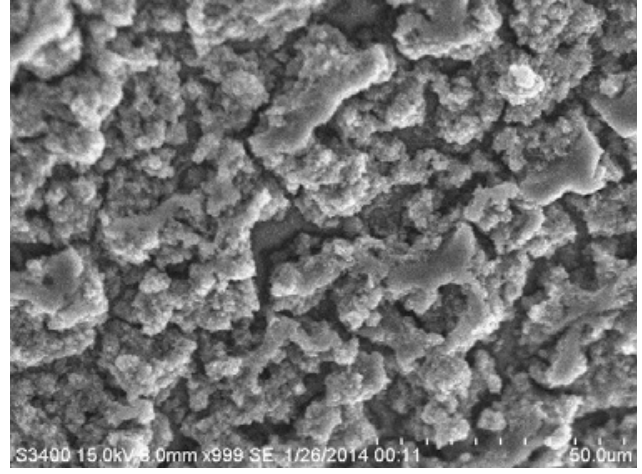

Figure 4. SEM image of $\mathrm{P} 25 \mathrm{TiO}_{2}$ immobilized on glass at 1000x magnification

It is also noted that catalyst entrainment cannot be assessed by surface characterization, as this would require the destruction of another reactor tube. Visual inspection of effluent samples, as well as reactor wash water, did not indicate any presence of entrained $\mathrm{TiO}_{2}$ particles. The small, if not negligible, extent of catalyst entrainment may be explained by the strong adhesion of the $\mathrm{P} 25 \mathrm{TiO}_{2}$ with the borosilicate glass, brought about by the use of ethanol as a carrier of the $\mathrm{TiO}_{2}$ suspension [18]. Due to the hydrophilic property of $\mathrm{P} 25 \mathrm{TiO}_{2}$ [20], the photocatalyst strongly adhered to the surface of the borosilicate glass, aided by the ethanol carrier.

\subsection{Reactor performance evaluation}

The performance of the reactor in the removal of methylene blue is shown in Figure 5. It confirms that the dominant mechanism for the removal of methylene blue is photocatalysis, with $57 \% \mathrm{MB}$ removal after 120 minutes. The contribution of adsorption is less than $20 \%$. The negligible extent of $\mathrm{MB}$ adsorption on $\mathrm{TiO}_{2}$ is consistent with other studies $[9,21]$.

The control runs, which include adsorption on the reactor walls, tubings, reservoir walls, and pump internals, account for an average of $12 \% \mathrm{MB}$ removal. It is also noted that the control runs are already at steady state as early as 30 minutes, implying that the adsorption of methylene blue on internal surfaces is fast, but contributes to a small extent only.

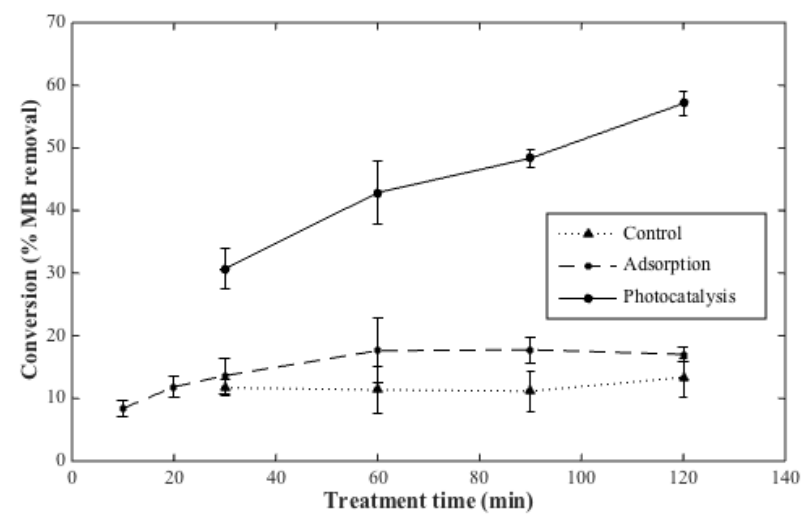

Figure 5. Photocatalytic reactor performance

The effect of sparging on reactor performance is illustrated in Figure 6. The highest conversion of the air- sparged reactor is $57 \%$ at 120 minutes, higher compared to the $40 \%$ of the non-sparged reactor, or greater by a factor of $1.4(40 \%)$. This validates the use of air sparging to improve reactor performance. The sparging of air into the system resulted to higher dissolved oxygen concentrations in the system. Oxygen serves as an electron-scavenger, taking in the excited electrons, thereby lessening electron-hole recombination. In addition, the rising air bubbles also facilitate better mixing inside the reactor tubes, further increasing the removal of methylene blue.

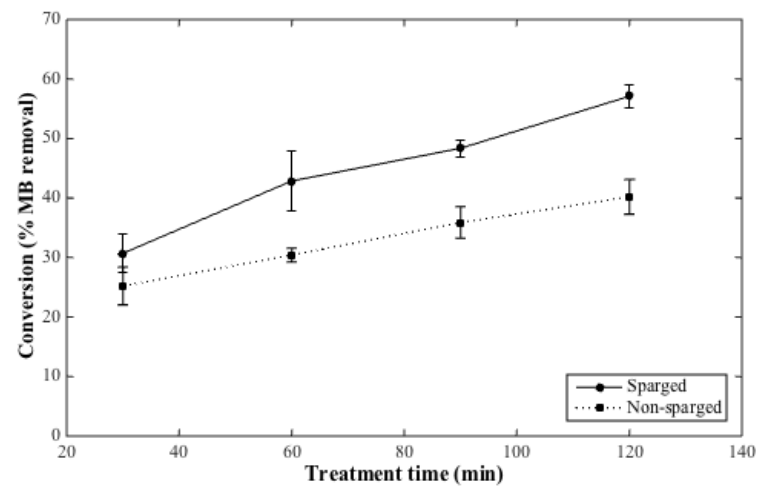

Figure 6. Effect of sparging on reactor performance

The reactor performs better than other reactors in related studies [21-23] and may be considered at par with some reactors [9], but with the advantage of using a simpler immobilization method (spray coating) and the use of less expensive materials of construction (borosilicate glass) [18].

\subsection{Mass-transfer limitation studies}

The equations for the initial reaction rate, $r$, in $\mu \mathrm{mol} / \mathrm{L}$ min, in terms of water flowrate, $Q$, for sparged and nonsparged operations are shown in equations (3) and (4), respectively. The rate is also plotted in Figure 7 below.

$$
\begin{aligned}
& r=0.1399 Q /(0.6120+Q) \\
& r=0.1024 Q /(0.4822+Q)
\end{aligned}
$$

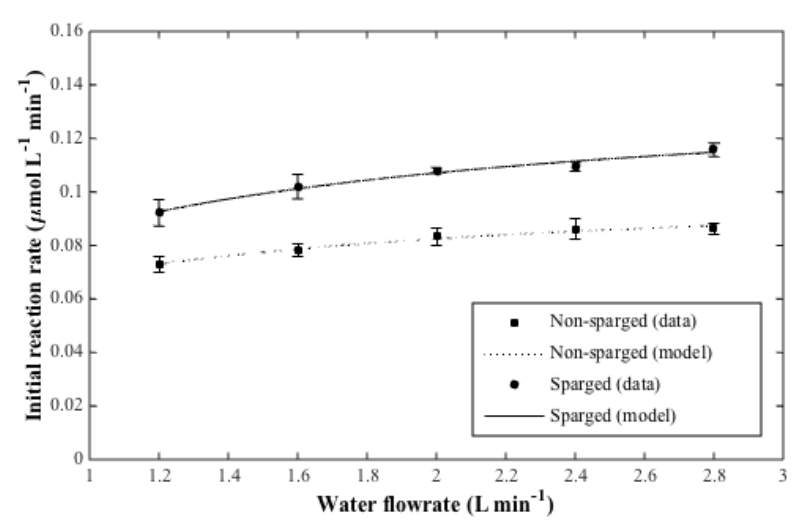

Figure 7. Effect of mass-transfer limitations on reactor performance

The experimental results gave rise to a good fit for both non-sparged and sparged reactor operation models, having $R^{2}$ values of 0.9825 and 0.9793 , respectively. This 
confirms a good fit to the Langmuir-type equation relating initial reaction rate with water flowrate. The small slopes seen in both models suggest that the studied range of flowrates is near the reaction-limited regime, and far from the diffusion-limited regime, which is characterized by relatively steep slopes. This observation becomes more obvious when the models are extrapolated to higher and lower flowrates, as seen in Figure 8. With this, it could be concluded that at the range of flowrates studied, particularly at the higher end of the range, the problem of mass-transfer limitations has been addressed by the present reactor [18].

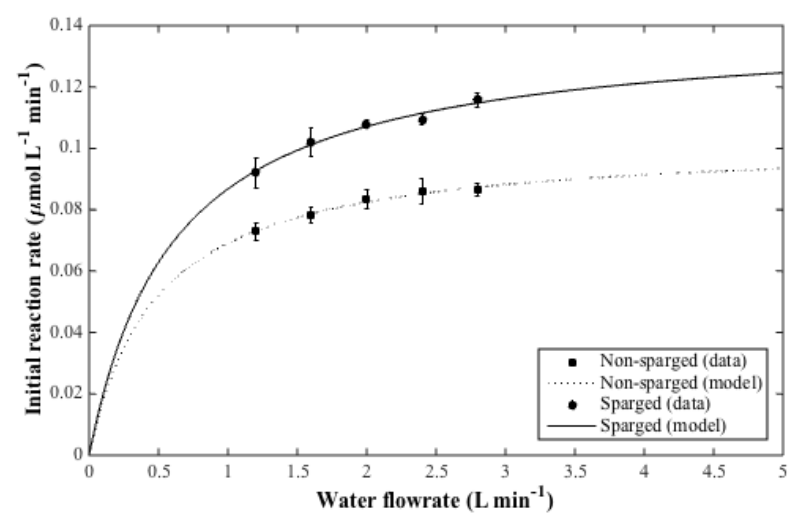

Figure 8. Effect of mass-transfer limitations on reactor performance (model extrapolated)

It is also noted from Figures 7-8 that the air-sparged reactor operates at higher rates of reaction than the nonsparged reactor, with maximum initial rates of 0.1157 and $0.0864 \mu \mathrm{mol} \mathrm{L}^{-1} \mathrm{~min}^{-1}$, respectively. This further supports the result that air sparging improved the performance of the reactor, as explained in the previous subsection.

\section{Conclusions}

An air-sparged tubular photocatalytic reactor with immobilized P25 $\mathrm{TiO}_{2}$ photocatalyst was designed to lessen electron-hole recombination and promote mixing. Surface characterization showed a good immobilization of $\mathrm{TiO}_{2}$ by spray coating and calcination; no observable catalyst entrainment was found by visual inspection of reactor effluents.

The dominant mechanism for methylene blue removal is photocatalysis, with negligible contribution of adsorption on $\mathrm{TiO}_{2}$ and other internal surfaces of the reactor. Air sparging improved the performance of the tubular photocatalytic reactor by a factor of $40 \%$. The reactor is comparable to the performance of other similar reactors in literature. However, the reactor of the present study offers an advantage of using a simpler immobilization technique and a less expensive material of construction.

Mass-transfer limitation studies indicate a good fit to a Langmuir-type equation in relating the initial reaction rate with the liquid volumetric flowrate. It also confirms that the present reactor operates closer to the reactionlimited regime, and that the extent of mass-transfer limitation effects has been lessened in this reactor.

\section{Acknowledgments}

The authors would like to acknowledge the Department of Science and Technology (Philippines) Engineering Research and Development for Technology (ERDT) Program for the financial assistance, and the University of the Philippines Department of Chemical Engineering for the use of laboratory and analytical equipment.

\section{References}

1. M.R. Hoffmann, S.T. Martin, W. Choi, D.W. Bahnemann, Chem. Rev., 95, 69-96 (1995)

2. R. Vinu, G. Madras, "Photocatalytic degradation of water pollutants using Nano-TiO ${ }_{2}$," in Energy Efficiency and Renewable Energy through Nanotechnology, L. Zang, Ed. London: Springer London, 625-677 (2011)

3. H. de Lasa, B. Serrano, M. Salaices, Photocatalytic Reaction Engineering. New York: Springer Science+Business Media, LLC (2005)

4. A. Mills, S. Le Hunte, J. Photochem. Photobiol. A Chem., 108, 1-35 (1997)

5. D. F. Ollis, E. Pelizzetti, N. Serpone, Environ. Sci. Technol., 25, 9, 1522-1529 (1991)

6. D. Chen, F. Li, A. K. Ray, Catal. Today, 66, 2-4, 475-485 (2001)

7. M. F. J. Dijkstra, E. C. B. Koerts, A. A. C. M. Beenackers, J. A. Wesselingh, AIChE J., 49, 3, 734744 (2003)

8. M. F. J. Dijkstra, H. Buwalda, A. W. F. De Jong, A. Michorius, J. G. M. Winkelman, A. A. C. M. Beenackers, Chem. Eng. Sci., 56, 547-555 (2001)

9. I. Boiarkina, S. Norris, D. Alec, Chem. Eng. J., 225, 752-765, (2013)

10. D. Chen, F. Li, A. K. Ray, AIChE J., 46, 5, 10341045, (2000)

11. M. F. J. Dijkstra, H. J. Panneman, J. G. M. Winkelman, J. J. Kelly, A. A. C. M. Beenackers, Chem. Eng. Sci., 57, 22-23, 4895-4907 (2002)

12. D. Dionysiou, M. T. Suidan, I. Baudin, J.-M. Laine, Appl. Catal. B Environ., 38, 1-16 (2002)

13. Y. Hama, M. Itamochi, T. Horikawa, M. Katoh, T. Tomida, J. Chem. Eng. Japan, 42, 7, 502-507 (2009)

14. B. Serrano, H. de Lasa, Ind. Eng. Chem. Res., 36, 4705-4711 (1997)

15. D. Chen, A. K. Ray, Appl. Catal. B Environ., 23, 143-157 (1999)

16. R. W. Matthews, J. Phys. Chem., 91, 25, 3328-3333 (1987)

17. A. H. Lim, K. B. Bautista, R. I. Sato, M. L. P. Dalida, Design and Performance of an Immobilized Photocatalytic Reactor for Water Treatment, B.S. thesis. Dept. Chem. Eng., Univ. of the Philippines Diliman, Quezon City, Philippines (2013)

18. P. D. Ramoso, M. L. P. Dalida, Design and Optimization of an Air-Sparged, TiO-Immobilized Tubular Photocatalytic Reactor for the Degradation of Methylene Blue, M.S. thesis. Dept. Chem. Eng., Univ. of the Philippines Diliman, Quezon City, Philippines (2014) 
19. M. Uzunova-Bujnova, R. Todorovska, M. Milanova, R. Kralchevska, D. Todorovsky, Appl. Surf. Sci., 256, 3, 830-837 (2009)

20. V. Bolis, C. Busco, M. Ciarletta, C. Distasi, J. Erriquez, I. Fenoglio, S. Livraghi, S. Morel, J. Colloid Interface Sci., 369, 1, 28-39 (2012)

21. K. Natarajan, T. S. Natarajan, H. C. Bajaj, R. J. Tayade, Chem. Eng. J., 178, 40-49 (2011)
22. S. Mozia, M. Toyoda, T. Tsumura, M. Inagaki, A. W. Morawski, Desalination, 212, 1-3, 141-151 (2007)

23. B. I. Stefanov, N. V. Kaneva, G. L. Puma, C. D. Dushkin, Colloids Surf. A Physicochem. Eng. Asp., 382, 1-3, 219-225 (2011) 